\title{
Review Article \\ The Potential Roles of Bisphenol A (BPA) Pathogenesis in Autoimmunity
}

\author{
Datis Kharrazian ${ }^{1,2}$ \\ ${ }^{1} 1001$ Canvasback Court, Carlsbad, CA 92011, USA \\ ${ }^{2}$ Division of Sciences, Bastyr University California, 4106 Sorrento Valley Boulevard, San Diego, CA 92121, USA \\ Correspondence should be addressed to Datis Kharrazian; datis56@gmail.com
}

Received 19 November 2013; Revised 20 January 2014; Accepted 12 February 2014; Published 7 April 2014

Academic Editor: Aristo Vojdani

Copyright (C) 2014 Datis Kharrazian. This is an open access article distributed under the Creative Commons Attribution License, which permits unrestricted use, distribution, and reproduction in any medium, provided the original work is properly cited.

\begin{abstract}
Bisphenol A (BPA) is a monomer found in commonly used consumer plastic goods. Although much attention in recent years has been placed on BPA's impact as an endocrine disruptor, it also appears to activate many immune pathways involved in both autoimmune disease development and autoimmune reactivity provocation. The current scientific literature is void of research papers linking BPA directly to human or animal onset of autoimmunity. This paper explores the impact of BPA on immune reactivity and the potential roles these mechanisms may have on the development or provocation of autoimmune diseases. Potential mechanisms by which BPA may be a contributing risk factor to autoimmune disease development and progression include its impact on hyperprolactinemia, estrogenic immune signaling, cytochrome P450 enzyme disruption, immune signal transduction pathway alteration, cytokine polarization, aryl hydrocarbon activation of Th-17 receptors, molecular mimicry, macrophage activation, lipopolysaccharide activation, and immunoglobulin pathophysiology. In this paper a review of these known autoimmune triggering mechanisms will be correlated with BPA exposure, thereby suggesting that BPA has a role in the pathogenesis of autoimmunity.
\end{abstract}

\section{Introduction}

Bisphenol A [2, 2 bis(4-hydroxyphenyl) propane; BPA] is a monomer used in the manufacture of polycarbonate plastics. BPA is used in diverse forms of plastic products in the food and electronic industries and in various types of commonly used consumer goods, such as plastic containers, utensils, toys, water bottles, and fax paper. BPA has been shown to leach out of products, and high levels of the monomer have been identified in human and animal samples [1]. The extensive use of BPA-containing products has resulted in high human exposure worldwide [2], with studies reporting that more than 90 percent of the US population has detectable levels in urine samples [3]. It appears that increased temperature leaches BPA into food and water products as does acidic $\mathrm{pH}$ of liquids [4]. Additionally, dermal contact with sales receipts and printer paper containing BPA compounds can lead to BPA exposure [5].

BPA has been studied extensively as an endocrine disruptor, and numerous papers have shown how BPA may impact perinatal, childhood, and adult health [6]. BPA has the ability to bind to estrogen receptors and promote both agonist and antagonist activity [7]. It also has the ability to bind to aryl hydrocarbon receptors and exert diverse adverse endocrine effects on human physiology [8]. Its impact on hormone signaling and endocrine dysfunction continues to be an area of research.

BPA also has been shown to have potential adverse neurological effects, especially with respect to fetal brain development and promotion of neurodegenerative diseases [9]. Mice models showing perinatal exposure to BPA inhibits synaptogenesis and affects synaptic structural modification after birth [10]. The impact of BPA on brain health and neurodevelopment also continues to be an area of research.

This paper explores the worldwide exposure to BPA and its potential role in the growing epidemic of autoimmune disease. Although no human or animal studies have been published linking BPA to the onset of autoimmune disease, the potential seems very high due to the physiological influences of BPA and current immunological models regarding loss of self-tolerance and autoimmunity. In addition to known immune mechanisms promoted by BPA that overlap with 


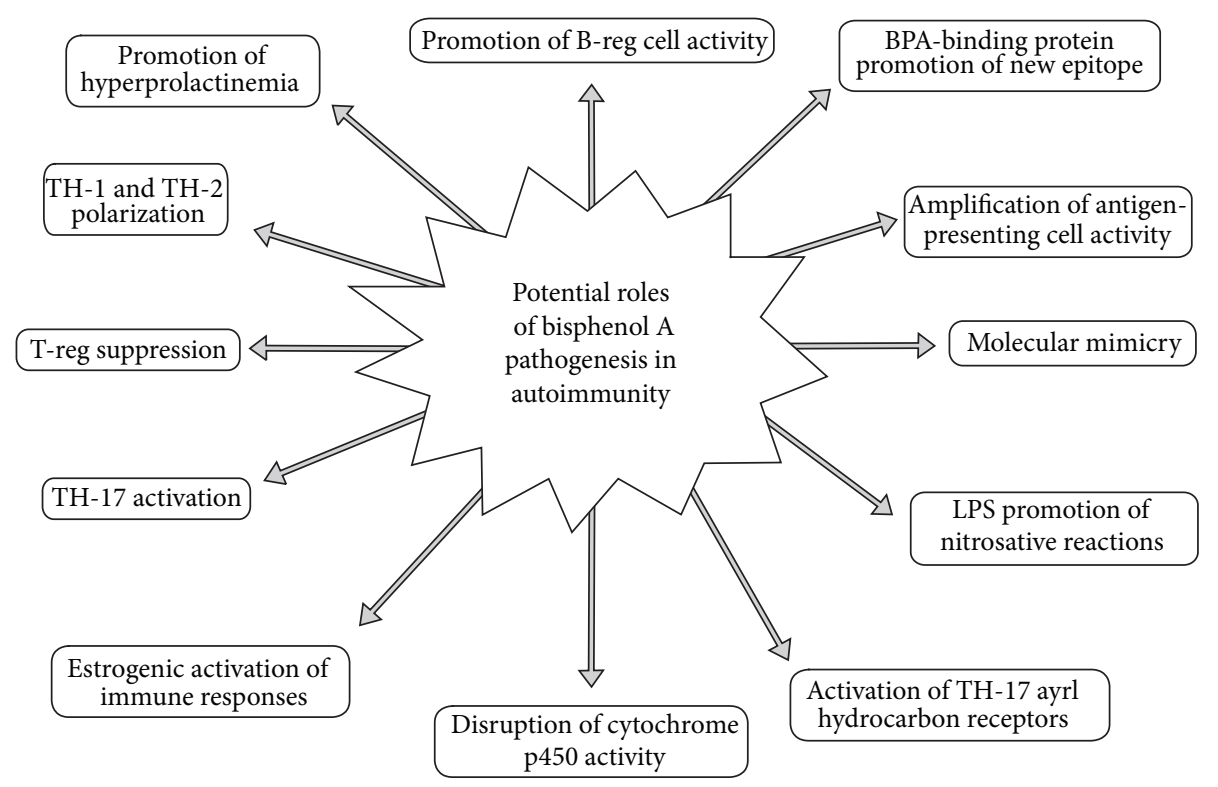

FIGURE 1: This diagram illustrates the potential mechanisms of bisphenol A's promotion of autoimmunity. BPA: bisphenol A; B-reg cell: regulatory B cell; LPS: lipopolysaccharide; TH: T-helper; T-reg: regulatory T cell.

autoimmune generation, some early evidence also indicates that BPA may contribute to mechanisms that promote autoimmune expression and progression (Figure 1).

\section{BPA, Hepatic Biotransformation, and Autoimmunity}

The hepatic biotransformation of BPA depends on phase I oxidation/reduction involving glutathione and phase II glucuronidation, glutathione, and sulfate conjugation [11]. Healthy humans exposed to BPA appear to have an accumulated body burden of BPA and monitoring studies that measure urinary BPA showed it stored in lipid reservoirs [12]. Despite proper hepatic biotransformation of BPA, the accumulation of BPA in body reservoirs may set the stage for immune reactivity and the onset of autoimmunity. Also, impaired hepatic clearance of circulating immune complexes in response to environmental compounds may induce autoimmunity. In a study of mice exposed to inorganic mercury, those mice that demonstrated reduced hepatic clearance of immune complexes also showed increased levels and altered quality of circulating immune complexes in mercury-induced autoimmunity [13]. Patients with abnormal hepatic biochemistries also have been shown to have a higher frequency of autoimmune disease [14].

A growing body of evidence shows increased toxic loads deplete hepatic tolerance, which leads to over activation of the innate and adaptive immune response and the development of autoimmune disease [15]. Higher BPA concentrations were associated with increased abnormal liver function tests [16]. Animal studies demonstrate that BPA has the ability to generate reactive oxygen species (ROS) and reduce antioxidant reserves and enzymes that are critical for hepatic phase I and II biotransformation, including glutathione, superoxide dismutase, glutathione peroxidase, glutathione S-transferase, glutathione reductase, and catalase activity [17].

BPA disruption of cytochrome P450 enzymes may be a potential mechanism for autoimmune pathophysiology. The cytochrome P450 (CYP) monooxygenases play a crucial role in the liver and various other tissues and are involved with oxidation of organic substances and the bioactivation of drugs and xenoestrogens [18]. CYP activity is necessary for the conversion of xenoestrogens into inactive metabolites that are both noninflammatory and biologically inactive. However, environmental xenoestrogens also have the potential to be metabolized into more reactive and inflammatory metabolites, thereby inducing increased ROS [19]. ROS are involved in apoptosis, activation of antigen presentation cells, and the initiation or amplification of diverse immunologic reactions that may be involved with the pathogenesis of autoimmune disease (Figure 2) [19].

Impairment of hepatic biotransformation of CYP expression may lead to ROS pathophysiology of autoimmunity. ROS have the ability to induce autoreactive molecules that may be involved with both the onset and the exacerbation of autoimmunity [20]. CYP enzymes are involved with metabolizing xenobiotics and producing ROS that may play a role in the pathophysiology of autoimmune disease.

In a study of mice offspring, BPA exposure to 15 and $300 \mathrm{mg} / \mathrm{L}$ of drinking water induced cytochrome CYP17 downregulation leading to potential proteomic alterations in immune function [21]. These mechanisms demonstrate the potential for BPA to disrupt proper CYP activity and potentially induce hepatotoxicity by promoting oxidative stress [17]. Increased production of ROS has demonstrated the ability to promote autoimmunity [22]. BPA activity has complex immune-activating reactions throughout the body. The impact of BPA on CYP enzyme expression may be a 


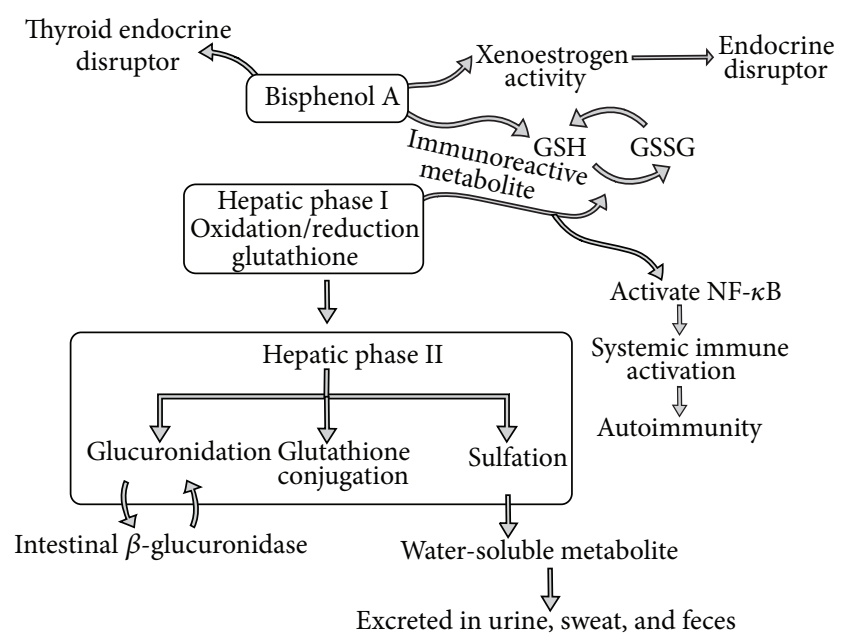

FIGURE 2: This diagram illustrates the hepatic biotransformation of bisphenol A. GSH: reduced glutathione; GSSG: oxidized glutathione.

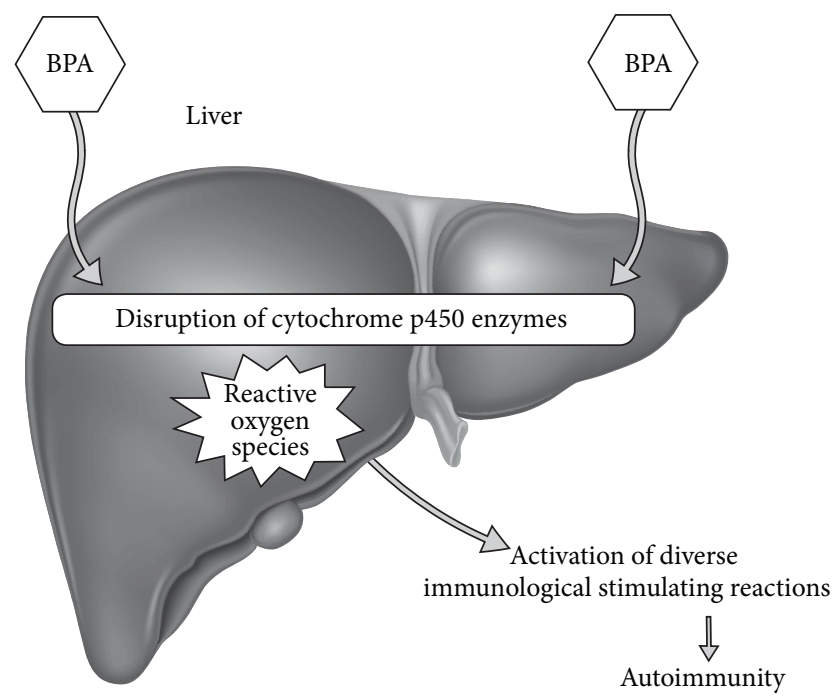

FIgURE 3: This diagram illustrates how bisphenol A can activate autoimmunity by disrupting cytochrome P450 enzymes. BPA: bisphenol A.

contributing mechanism to BPA autoimmune pathophysiology (Figure 3).

\section{BPA Impact on Prolactin Synthesis and Autoimmunity}

Although the peptide hormone prolactin is known primarily for its role in lactation, it also plays a critical role in modulating immune and inflammatory responses through various immune signaling pathways [23]. Prolactin has been shown to play significant roles in antigen presenting functions and in the initiation of the response against major histocompatibility complex (MHC) presenting self-antigens as found in autoimmunity [24].
A review of hyperprolactinemia and autoimmunity has found increased prolactin levels associated with production of anti-DNA antibodies, islet cell antibodies, thyroglobulin antibodies, thyroid peroxidase antibodies, adrenocortical antibodies, and transglutaminase antibodies with individuals suffering from systemic lupus erythematosus (SLE), diabetes mellitus type 1, Hashimoto's disease, Addison's disease, and celiac disease [25]. Prolactin has profound immunological stimulating, enhancing, and proliferative responses to antigens and mitogens by promoting increased cytokine activity and immunoglobin production. It also interferes with B cell tolerance and has autoimmune promoting effects [26].

BPA is an endocrine disruptor with powerful effects on the pituitary lactotroph cells, which are estrogen responsive and promote prolactin release. In vitro and in vivo studies have found that BPA mimics estradiol and induces hyperprolactinemia [27]. Therefore, BPA has potential impacts on autoimmune disease activation via its impact on increasing the immunostimulatory response of prolactin (Figure 4).

A link between BPA exposure and increased prolactin levels was found in women workers in occupational settings within one year. They demonstrated marked prolactin level increases and a multivariate analysis found BPA exposure was an independent risk factor for increased serum prolactin levels [28].

The correlation between hyperprolactinemia and autoimmune disease promotion has been reported in the literature in multiple papers during the past 20 years [29]. Additionally, recent evidence has found that BPA has major stimulatory impacts on prolactin release. These correlations strongly suggest that BPA may promote autoimmune pathophysiology by increasing prolactin release that then promotes immunestimulating activity.

\section{BPA and Estrogenic Activation of Immune Responses}

In addition to the impact of BPA on prolactin release through its estrogenic influence on pituitary cells, BPA also appears to directly affect immune cell signaling pathways and thus immune responses [30]. BPA is classified as an endocrine disruptor in the form of a xenoestrogen and has the potential to mimic estrogen activity throughout the body [31]. This is important because increased circulating estrogens have demonstrated relationships with greater autoimmune activity [32]. Furthermore, epidemiological evidence suggests that the significant increase in the prevalence of autoimmune disease may in part be attributed to environmental estrogens (xenoestrogens). A review of the role of estrogens provides reasonable evidence of an association between xenoestrogen exposure and autoimmune disorders [33].

Various estrogen-promoted mechanisms have been found to trigger autoimmune reactivity. The reticulum transmembrane protein UNC93B1, which is essential for trafficking toll-like receptors (TLRs) from endoplasmic reticulum and is found to play a role in autoimmunity, has been shown to be upregulated by estrogenic signaling [34]. Estrogen activity has also been shown to directly and indirectly stimulate 


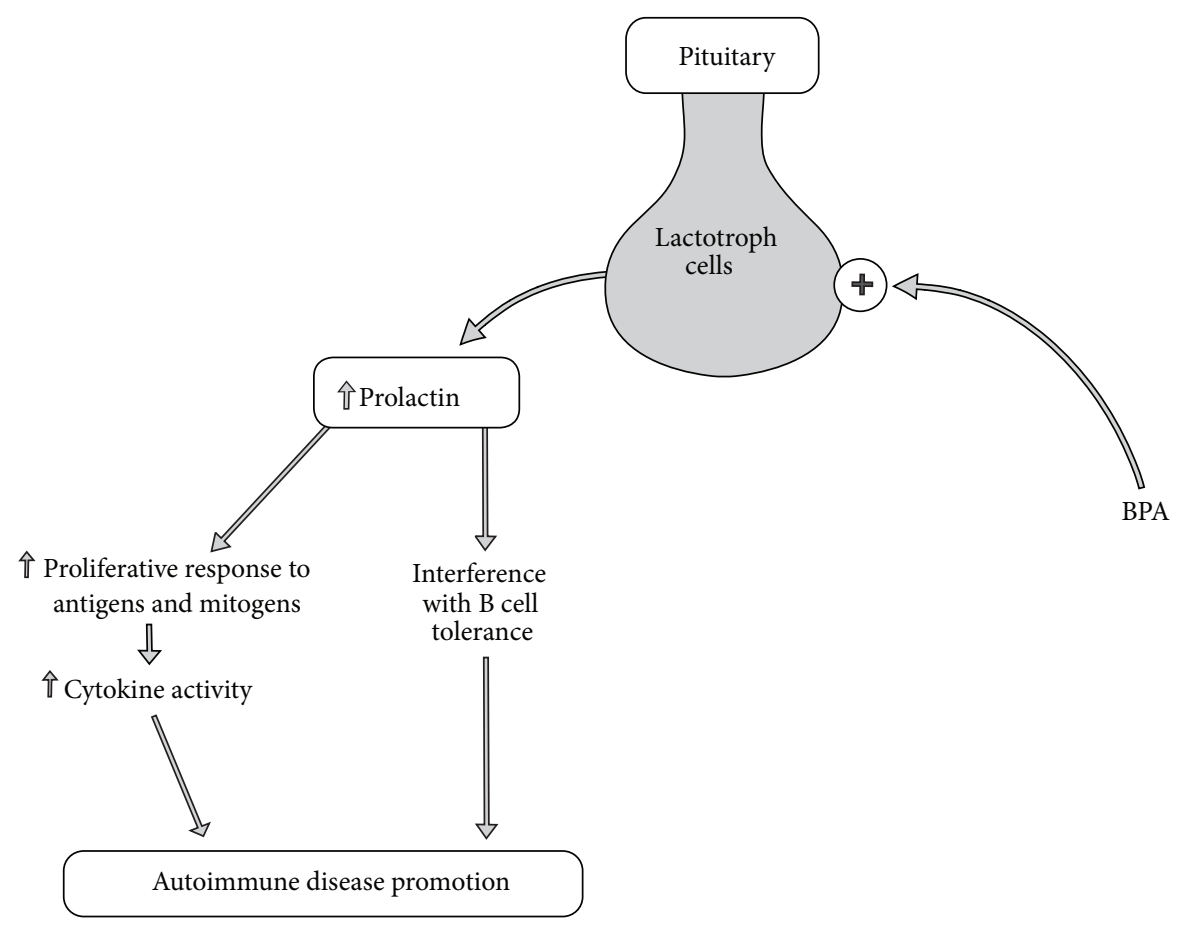

FIGURE 4: This diagram illustrates how bisphenol A can activate hyperprolactinemia and increase immunostimulatory responses, promoting autoimmunity. BPA: bisphenol A.

activation-induced deaminase (AID), leading to immune hyperstimulation. AID plays an important role in immune tolerance and the actual elimination of autoantibodies that may impact autoimmune reactivity [35]. Estrogen activity appears to promote signaling of T cell activation in autoimmunity [36]. Estradiol impacts macrophage production of tumor necrosis factor alpha [37]. Treatment of immune cells with estradiol has been shown to increase levels of $B$ cell activating factor (BAFF) mRNA and protein that are associated with increasing severity of autoimmune disease expression [38]. Estrogen activity appears to impact dendritic cell differentiation and interferon production [39]. In summary, estrogen activity appears to have diverse and complex modulatory and stimulating roles in the immune system [40].

Many of these immune-stimulating responses that perpetuate chronic inflammation and autoimmunity may also be potentiated by the estrogenic activity of BPA [41]. BPA stimulates cell proliferation and induced expression of estrogen responsiveness. It also stimulates uterine, vaginal, and mammary growth and differentiation in vivo [42]. BPA treatment in mice induced splenocyte proliferation, a shift of cytokine profiles from Th-2 to Th-1 activity, and hyperstimulation of cellular immunity similar to patterns associated with Th-1 dominant autoimmune disease [43]. Overall, BPA has multiple estrogenic mechanisms in promoting abnormal immune responses that include altering $\mathrm{T}$ cell subsets, $\mathrm{B}$ cell functions, and dendritic cell activity and inducing abnormal immune signaling via its disruptive impact on estrogen receptor signaling, aryl hydrocarbon receptor signaling, and abnormal signaling of peroxisome proliferator-activated nuclear receptors [44]. These BPA estrogenic impacts on virtually all the major cells of the immune system and critical signaling pathways may be one way in which BPA promotes pathogenesis of autoimmunity (Figure 5).

\section{BPA Impact on Immune Signaling Pathways}

BPA has hapten and estrogenic activity, both of which play roles in activating hyperactive immune responses that may occur in autoimmune pathophysiology.

BPA exposure leads to aquatic animal hemocyte immune dysfunction, potentially increasing its role in induced autoimmunity through immune dysregulation. BPA injected into mussels leads to significant lysosomal membrane destabilization and a dramatic decrease in phosphorylation of the stress-activated p38 mitogen-activated protein kinases (MAPKs) and CREB-like transcription factor (cAMPresponsive element-binding protein) in mussels [45]. These results indicate BPA-induced alteration of hemocyte signal transducers and activator of transcription (STAT). These MAPK and STAT pathways are crucial in normal signaling to prevent upregulation of autoreactive $\mathrm{T}$ cells found to induce autoimmune inflammatory reactivity [46].

In addition to turning on gene expression of autoreactive $\mathrm{T}$ cells, alterations in these MAPK and STAT signaling pathways lead to chronic activation of antigen-presenting cells (APCs), loss of regulatory T cells (CD4+CD25+), apoptosis of APCs, and inhibition of innate and adaptive immunity wind-up found in the pathogenesis of autoimmunity [47]. The signaling pathways that are activated by BPA exposure have been shown to be the exact signaling pathways of molecular processes in autoimmune disease pathophysiology [48]. 


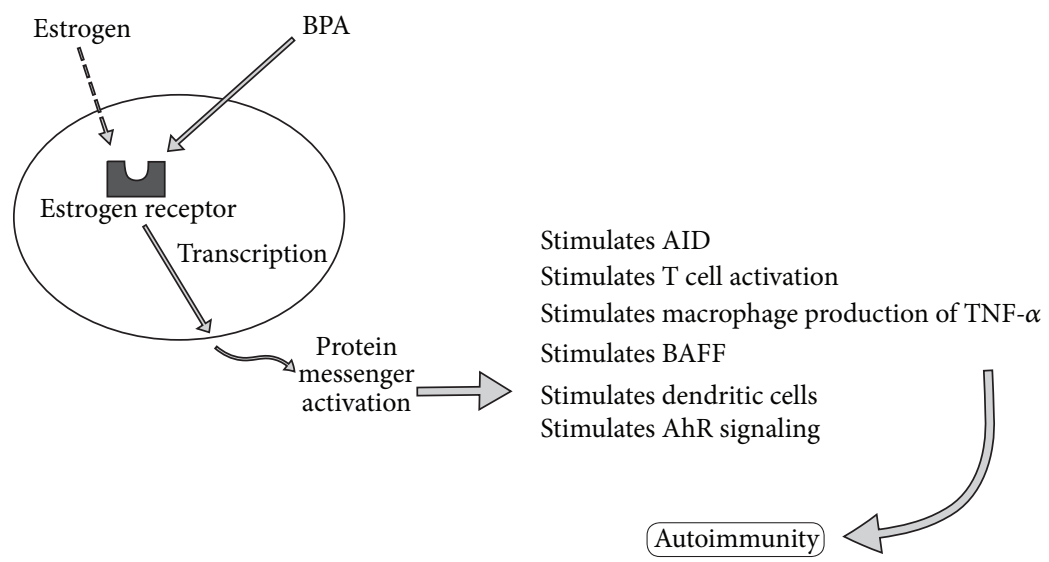

Figure 5: This diagram illustrates how bisphenol A can bind to estrogen receptors and promote estrogenic-mediated autoimmunity. AID: activation-induced deaminase; BAFF: B cell activating factor; BPA: bisphenol A; TNF-alpha: tumor necrosis factor alpha; AhR: aryl hydrocarbon.

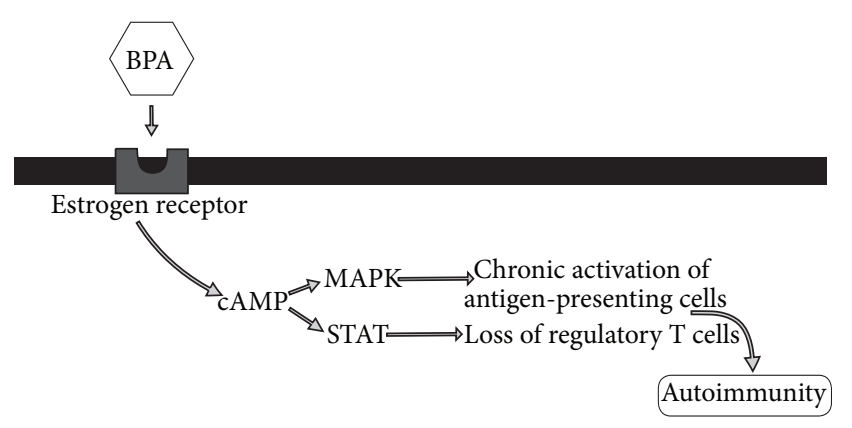

Figure 6: This diagram illustrates how bisphenol A can promote autoimmunity by cellular transcription activation. BPA: bisphenol A; cAMP: adenosine $3^{\prime} 5^{\prime}$-cyclic monophosphate; MARK: mitogenactivated protein kinase; STAT: signal transducer and activator of transcription.

Therefore, BPA activity as either an estrogenic endocrine disruptor or hapten-activating structure seems to specifically disrupt immune signaling pathways found in autoimmune disease (Figure 6).

\section{BPA and Cytokine Expression}

Cytokines have been shown to play a key role in the pathogenesis of autoimmune disease. The shift of cytokines into Th1/Th-2 dominance and the IL-17/IL-23 (Th-17) axis has been shown to play pivotal roles in the model of autoimmunity and the breakdown of self-tolerance [49]. BPA has been shown to impact the differentiation processes of the dendritic cells that may cause unintended activation of the immune system in the absence of pathological conditions, thus promoting inappropriate polarization of $\mathrm{T}$ cells and cytokine profiles and shifting the immune system into an overzealous immunological state [50]. Additionally, BPA exposure prenatally to mice with oral feeding induced upregulation of Th-1 responses in adulthood [51].
The impact of BPA on naïve immune systems using T cell receptor transgenic mice followed by measurement of cytokine responses to antigens suggest that BPA can augment Th1 reactions when administered orally in low doses ( $1.5 \mathrm{mg}$ to $1.8 \mathrm{mg} / \mathrm{kg}$ weight) in water. Specifically BPA increased antigen-specific interferon gamma production leading to exaggerated $\mathrm{T}$ cell activation and polar Th-1 and Th- 2 shifts [52]. These mechanisms associated with interferon have been shown to play powerful effector roles in the pathogenesis of autoimmunity, especially system autoimmunity such as systemic lupus erythematosus [53].

Animal studies have also shown that BPA exposure promotes cytokine inflammatory shifts associated with potential autoimmune development. BPA administered to mice in drinking water produced significant shifts of lymphocytes subpopulations. The production of inflammatory Th-1 type cytokines (IFN-gamma) was induced while Th-2 cytokine (IL-4) was suppressed with BPA treatment, promoting the transcription of IRF-1. The mRNA expression of GATA-3 was inhibited in BPA-treated groups in dosages of 0.015, 1.5, and $30 \mathrm{mg} / \mathrm{mL}$ for 4 weeks [54]. These responses indicated that BPA has the potential to induce Th-1 polar shifts of transcription factor that lead to exaggerated cellular immune responses leading to an exaggerated Th-1 immune response. The suppression of GATA-3 transcription factors and T cell polarization favoring a Th-1 bias has been shown to be an immune mechanism of multiple sclerosis autoimmunity in animals [55].

A study comparing the effect of BPA exposure on cytokine activity in adulthood and prenatally demonstrated that in adulthood exposure to BPA significantly promoted antigen-stimulated production of IL-4, IL-10, and IL-13, but not IFN-gamma. However, mice exposed prenatally to BPA showed increased production of not only IL-4 but also IFN-gamma. The percentages of $\mathrm{T}$ regulatory function $(\mathrm{CD} 4+\mathrm{CD} 25+)$ were decreased in both groups exposed to BPA [56]. Loss of regulatory $\mathrm{T}$ cell function promotes abnormal cytokine shifts that occur in autoimmune diseases [57]. Suppression of regulatory $\mathrm{T}$ cell function leading to impaired 


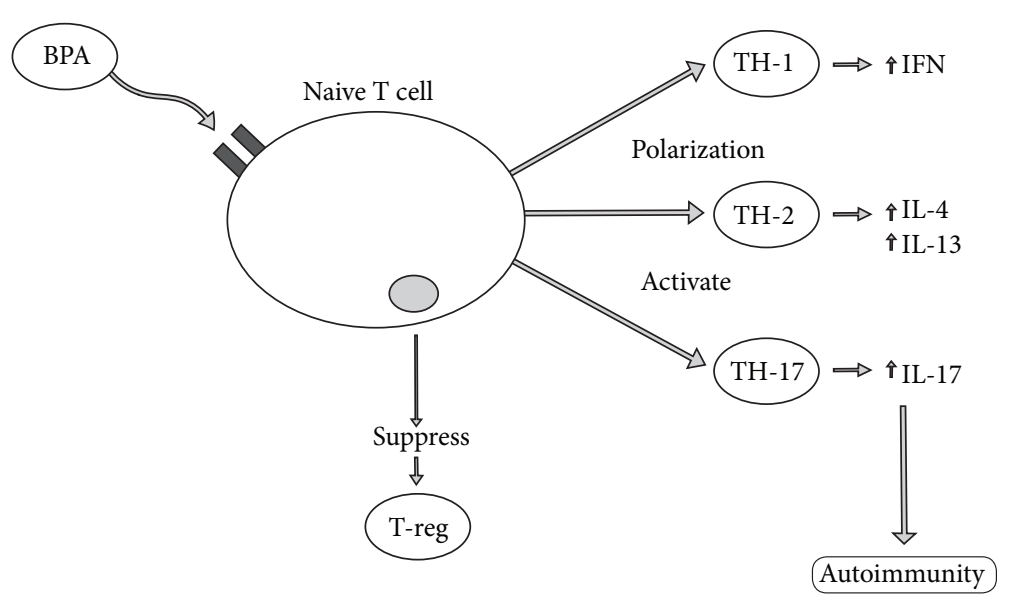

FIGURE 7: This diagram illustrates how bisphenol A can induce T cell shifts, promoting autoimmunity. BPA: bisphenol A; IFN: interferon; IL: interleukin; TH: T-helper; T-reg: regulatory T cell.

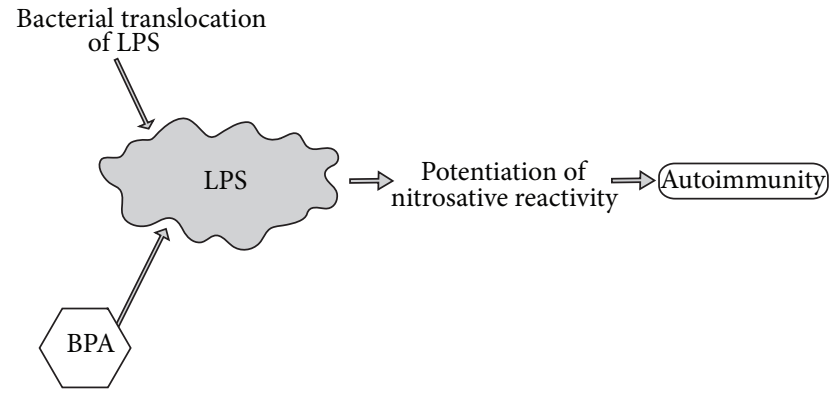

Figure 8: This diagram illustrates how bisphenol A can promote lipopolysaccharide inflammatory sequelae. BPA: bisphenol A; LPS: lipopolysaccharide.

cytokine modulation may be part of the immunopathology of BPA autoimmune development.

The delicate interplay between Th-1, Th-2, and Th-17 expression appear to be a key factor in autoimmune pathophysiology. Evidence indicates that BPA may induce polarity in this delicate balance and trigger inflammatory reactions, potentially leading to loss of self-tolerance as noted in subsequent paragraphs. The impact of BPA on the pathogenesis of abnormal cytokine shifts most likely occurs from complex web-like reactions. BPA's role as both a hapten and estrogenic endocrine disruptor appears to promote multiple interwoven pathways involved in adverse cytokine shifts that may play a role in autoimmune pathogenesis (Figure 7).

\section{BPA and Lipopolysaccharide-Induced Nitric Oxide Production}

Bacterial translocation of lipopolysaccharides (LPS) has the ability to activate oxidative and nitrosamine stress pathways associated with the inflammatory responses and pathophysiology of autoimmune responses [58]. BPA directly impacts LPS activation of these pathways, and the role of BPA on LPS activation could likewise play a role in abnormal immune reactivity [59].

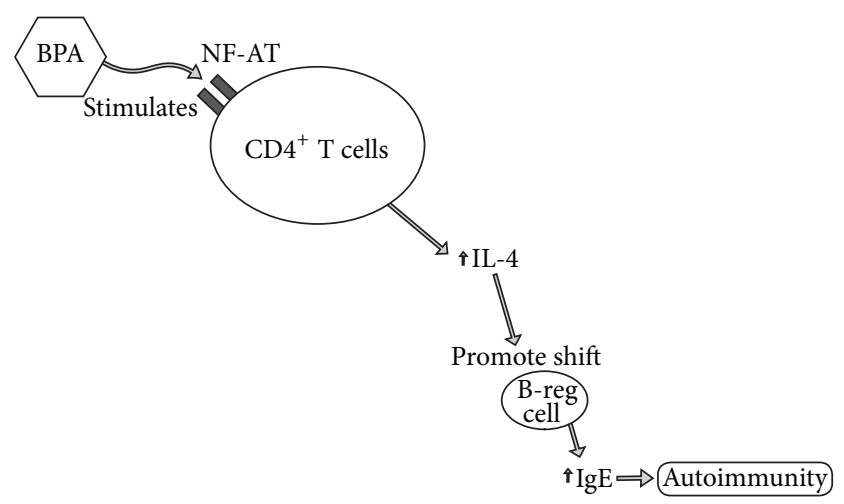

FIgURE 9: This diagram illustrates how bisphenol A can impact immunoglobulin-promoted autoimmunity. BPA: bisphenol A; B-reg cell: regulatory B cell; IL: interleukin; IgE: immunoglobulin E; NF$\mathrm{AT}: \mathrm{Ca}^{+} /$calcineurin-dependent nuclear factor binding sites.

Additionally, decreased activation of LPS-induced inflammatory reactions has also demonstrated a reduction in inflammatory sequelae of autoimmune cytokine and chemokine expression. Specifically, mice injected with BPA exhibited increased endotoxin-induced macrophage activation, suggesting that BPA may potentiate infectious autoimmune inflammatory reactions via enhanced tumor necrosis factor and nitric oxide reactivity [60]. Therefore, LPS-induced expression of nitrosative stress reactivity may be a key factor in BPA-promoted models of autoimmunity associated with infectious autoimmune reactions (Figure 8).

\section{BPA Impacts on Antigen-Presenting Cell Reactivity}

Antigen-presenting cells such as dendritic cells and macrophages appear to play a potential role with BPA and autoimmune reactivity. Dendritic cells (DCs) are important antigenpresenting cells that play a critical role in adaptive immunity due to their ability to activate naive $\mathrm{T}$ cells, which, when 


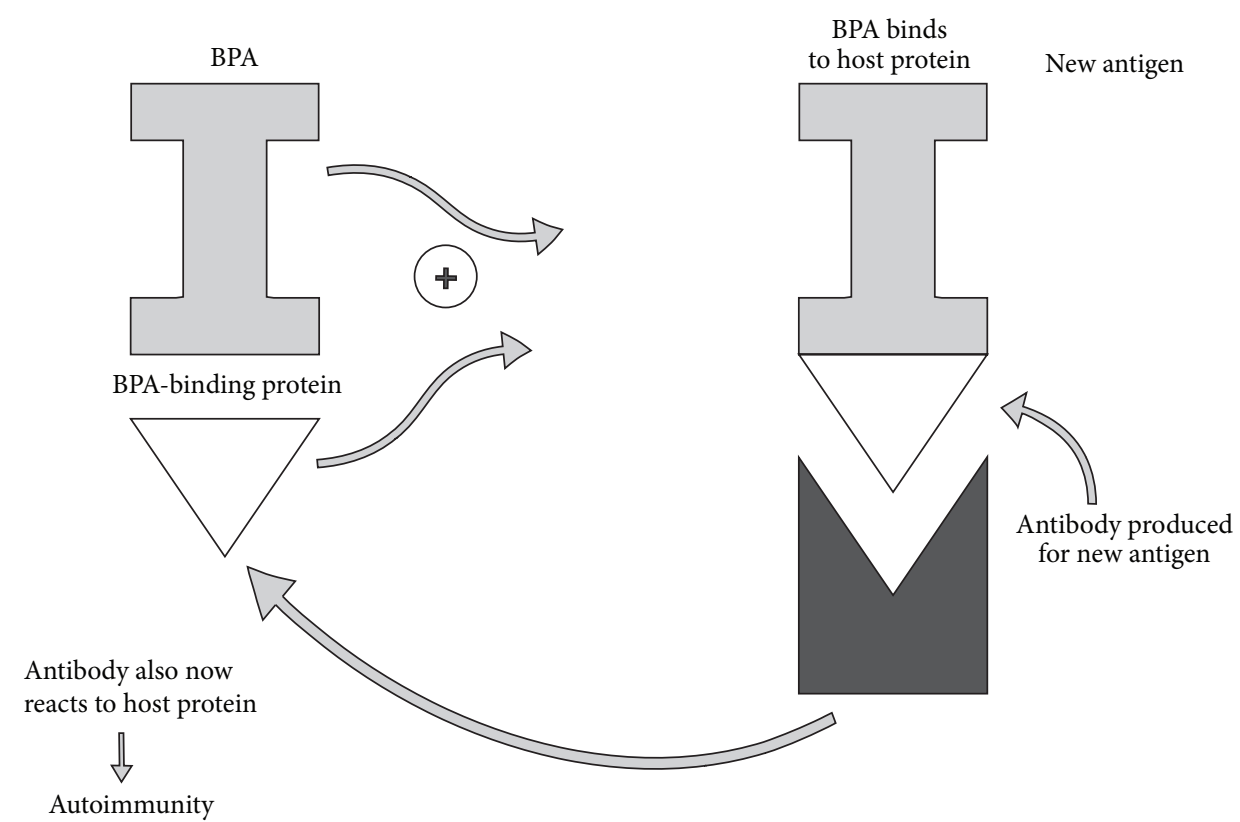

FIgURE 10: This diagram illustrates how bisphenol A can bind to the host protein, leading to a new epitope reaction against the host protein, resulting in autoimmunity. BPA: bisphenol A.

overzealous, could promote autoimmune activity [61]. DCs promote the expressions of Th-1, Th-2, or Th-17 cells that can be switched to express autoimmune inflammatory cascades [62]. DCs exposed to BPA in combination with tumor necrosis factor alpha promote CC chemokine ligand 1 (CCL1) signaling, a chemokine that is known to trigger chemotaxis of CCr8 expressing Th-2 and a subset of T regulatory cells, thereby promoting higher levels of IL-10 relative to those of IL-12p70 on CD40 ligation and preferentially inducing Th-2 deviation [63]. These variant responses from DCs exposed to BPA may play a role in autoimmunity.

Macrophage modulation of nitric oxide release is also critical for the regulation of apoptosis and differentiation of $\mathrm{T}$ cells that may lead to progression of autoimmune disease [64]. Additionally, BPA exposure has the ability to exert disruptive effects on macrophages by binding to estrogen receptors and leading to alteration of nitric oxide production and TNF-alpha synthesis in the homeostasis of TH-1 and TH-2 activity [65]. These macrophage expressions from BPA may promote immunological shifts that occur with autoimmunity, linking BPA's potential role to abnormal antigenpresenting cell responses.

\section{BPA Effects on Immunoglobulin Activity}

Increased immunoglobulin reactivity from endocrine disruptors such as BPA may raise concerns about immune hyperactivity associated with autoimmune immunopathology. The activation of immunoglobulins has a potential to promote inflammatory or anti-inflammatory activities through the activation of regulatory B (Breg) cells. Recent research in mice has shown that when $B$ cell expression shifts into IL-10 production, there are suppressive effects on inflammatory responses. However, promotion of IgE-producing B cells plays a direct role in promoting inflammatory responses and the development of immune upregulation associated with most underlying inflammatory conditions, such as allergies and autoimmunity [66].

Recent research has shown that BPA has a direct impact on increasing immunoglobulin expression into the inflammatory $\operatorname{IgE}$ response, thereby potentially promoting an inflammatory cascade in autoimmunity. Specifically, exposure to BPA was shown to increase IL- 4 production in $\mathrm{CD} 4^{+}$ $\mathrm{T}$ cells and antigen-specific IgE levels in sera via the stimulation of $\mathrm{Ca}^{2+} /$ calcineurin-dependent nuclear factor of activated $\mathrm{T}$ cells binding sites (NF-AT) [67]. These immune responses have the ability to potentiate allergies and autoimmune reactions in those with autoimmunity. Increased levels of IgE may play a direct role in promoting the inflammatory responses found in autoimmunity [68]. The potential for BPA to increase IL-4 and promote a shift of Breg cells into IgE production may be a mechanism for BPA autoimmune promotion (Figure 9).

In a murine model for SLE, animals implanted with BPA specifically demonstrated B cell activation and promotion of autoimmune disease such as lupus nephritis. BPA implantation enhanced autoantibody production by $\mathrm{B} 1$ cells both in vitro and in vivo in murine models of SLE. The study researchers suggested that BPA exacerbates preexisting autoimmune diseases such as SLE and that continued exposure to endocrine disruptors may potentiate the incidence and severity of autoimmune diseases [69].

Evidence of BPA on expressing B cell activity towards inflammatory expression and autoimmune development may partly explain the complex immune web reactions of this endocrine disruptor. Although inflammatory immunoglobulin reactivity may have a role to play in autoimmune expression, it is most likely part of a larger complex immune 
<smiles>CC(C)(c1ccc(O)cc1)c1ccc(O)cc1</smiles>

Bisphenol A<smiles>NC(Cc1ccc(Oc2cc(I)c(O)c(I)c2)c(I)c1)C(=O)O</smiles>

Triiodothyronine

FIGURE 11: This diagram illustrates the structural similarity between bisphenol A and triiodothyronine, leading to potential cross-reactivity.

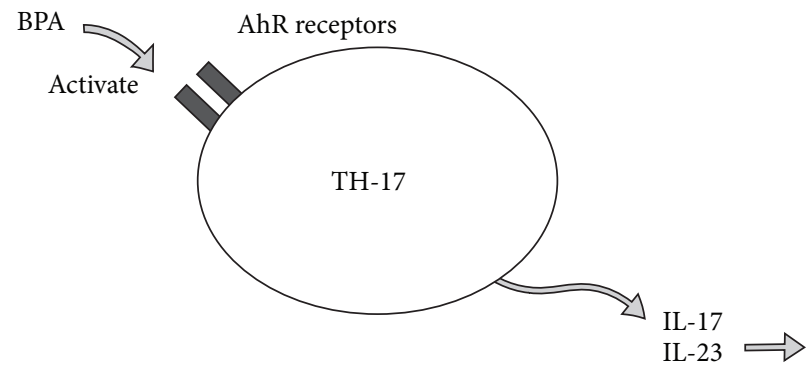

FIGURE 12: This diagram illustrates how bisphenol A can activate autoimmunity by inducing mRNA expression on aryl hydrocarbon receptors on TH-17 cells. AhR: aryl hydrocarbon; BPA: bisphenol A; IL: interleukin; TH: T-helper.

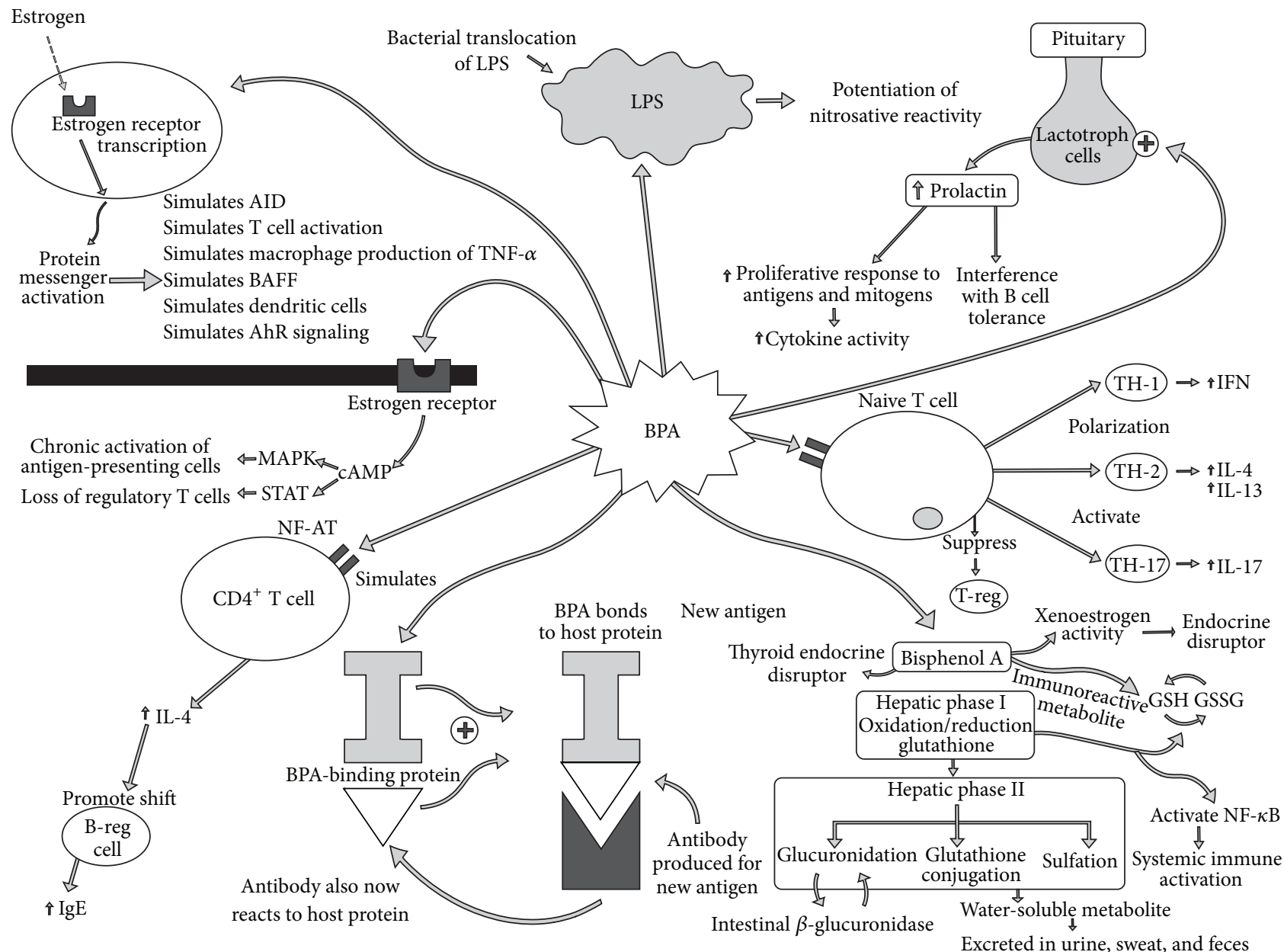

Figure 13: Potential of various autoimmune mechanisms from bisphenol A. 
reaction that is linked to this very reactive endocrine disruptor.

\section{BPA-Binding Protein: A Potential New Epitope}

BPA binds to host protein, potentially creating a new epitope for immune reactivity. BPA binds to protein disulfide isomerase (PDI), also known as BPA-binding protein [70], a multifunctional protein involved in diverse cellular functions. This binding protein has been associated with endocrine disruptor mechanisms involving BPA [71]. The binding of environmental BPA to host protein may lead to self-tissue, antigen-antibody interactions associated with environmentally induced molecular mimicry. Autoimmune molecular mimicry requires the similarities of surface topologies leading to antigenic combining sites [72]. The binding of BPA to PDI in host has the potential to lead to new protein epitope activation of autoimmunity (Figure 10).

\section{BPA and Autoimmune Molecular Mimicry}

BPA and triiodothyronine (T3) possess such a degree of molecular structure similarity that BPA may act as an antagonist compound on T3 receptor sites [73]. When compounds have structural similarity, it may potentially lead to autoimmune cross-reactivity with antigen-antibody complexes [74]. In particular, environmental compounds such as hydrocarbon rings found both on BPA and $\mathrm{T} 3$ with anchor ring like similarities may induce mimicry [75]. A potential mechanism for the role of BPA in autoimmunity may be structural molecular mimicry, in particular with thyroid hormones (Figure 11).

\section{BPA and TH-17 Aryl Hydrocarbon Receptors}

Aryl hydrocarbon receptors (AhR) are involved with regulating immune responses and the development of TH-17 cells, which are key effector $\mathrm{T}$ cells in a variety of human autoimmune diseases. [76] Exposure to low dose BPA has been shown to upregulate mRNA expressions of AhR. AhR activation of TH-17 by BPA may potentiate autoimmunity. The role of chemical contamination and its ability to prompt AhR receptor activation of $\mathrm{TH}-17$ have already been investigated in allergic and autoimmune diseases [77]. Although direct evidence has not been investigated for the role of BPA on AhR activation of TH-17 autoimmune reactivity, the potential mechanism may exist (Figure 12).

\section{Conclusion}

With the growing epidemic of autoimmune disease worldwide and the extensive use of consumer goods containing $\mathrm{BPA}$, we must examine the risk of BPA as a potential triggering compound in autoimmune disease. Although no specific evidence has linked human or animal autoimmune disease development to BPA exposure, many of the mechanisms known to exist in autoimmune pathophysiology also appear to exist with immune reactivity from BPA exposure (Figure 13). Further investigation needs to be conducted correlating autoimmune disease development to BPA exposure. Additionally, the impact of BPA exposure on those already suffering from autoimmunity needs to be investigated further based on potential overlapping pathophysiology.

\section{Conflict of Interests}

The author declares that there is no conflict of interests regarding the publication of this paper.

\section{References}

[1] J. A. McLachlan, "Environmental signaling: what embryos and evolution teach us about endocrine disrupting chemicals," Endocrine Reviews, vol. 22, no. 3, pp. 319-341, 2001.

[2] L. N. Vandenberg, I. Chahoud, J. J. Heindel, V. Padmanabhan, F. J. R. Paumgartten, and G. Schoenfelder, "Urinary, circulating, and tissue biomonitoring studies indicate widespread exposure to Bisphenol A," Ciencia e Saude Coletiva, vol. 17, no. 2, pp. 407434, 2012.

[3] A. M. Calafat, X. Ye, L.-Y. Wong, J. A. Reidy, and L. L. Needham, "Exposure of the U.S. population to Bisphenol A and 4-tertiaryoctylphenol: 2003-2004," Environmental Health Perspectives, vol. 116, no. 1, pp. 39-44, 2008.

[4] W. V. Welshons, S. C. Nagel, and F. S. vom Saal, "Large effects from small exposures. III. Endocrine mechanisms mediating effects of Bisphenol A at levels of human exposure," Endocrinology, vol. 147, no. 6, supplement, pp. S56-S69, 2006.

[5] S. Biedermann, P. Tschudin, and K. Grob, “Transfer of Bisphenol A from thermal printer paper to the skin," Analytical and Bioanalytical Chemistry, vol. 398, no. 1, pp. 571-576, 2010.

[6] J. R. Rochester, "Bisphenol A and human health: a review of the literature," Reproductive Toxicology, vol. 42, pp. 132-155, 2013.

[7] H. Hiroi, O. Tsutsumi, M. Momoeda, Y. Takai, Y. Osuga, and Y. Taketani, "Differential interactions of Bisphenol A and 17 $\beta$ estradiol with estrogen receptor $\alpha(\mathrm{ER} \alpha)$ and $\mathrm{ER} \beta$," Endocrine Journal, vol. 46, no. 6, pp. 773-778, 1999.

[8] E. C. Bonefeld-Jørgensen, M. Long, M. V. Hofmeister, and A. M. Vinggaard, "Endocrine-disrupting potential of Bisphenol A, Bisphenol A dimethacrylate, 4-n-nonylphenol, and 4-n-octylphenol in vitro: new data and a brief review," Environmental Health Perspectives, vol. 115, supplement 1, pp. 69-76, 2007.

[9] K. A. Szychowski and A. K. Wójtowicz, "Components of plastic disrupt the function of the nervous system," Postępy Higieny $i$ Medycyny Doświadczalnej, vol. 67, pp. 499-506, 2013.

[10] X. Xu, L. Xie, X. Hong et al., "Perinatal exposure to Bisphenol-A inhibits synaptogenesis and affects the synaptic morphological development in offspring male mice," Chemosphere, vol. 91, no. 8, pp. 1073-1081, 2013.

[11] H. Kurebayashi, H. Betsui, and Y. Ohno, "Disposition of a low dose of 14C-Bisphenol A in male rats and its main biliary excreation as BPA glucuronide," Toxicological Sciences, vol. 73, no. 1, pp. 17-25, 2003.

[12] K. L. Christensen, M. Lorber, S. Koslitz, T. Brüning, and H. M. Koch, "The contribution of diet to total Bisphenol A body burden in humans: results of a 48 hour fasting study," Environment International, vol. 50, pp. 7-14, 2012. 
[13] K. Martinsson, T. Skogh, S. Mousavi, T. Berg, J.-I. Jönsson, and P. Hultman, "Deficiency of activating Fc $\gamma$-receptors reduces hepatic clearance and deposition of IC and increases CIC levels in mercury-induced autoimmunity," PLoS ONE, vol. 5, no. 10, Article ID e13413, 2010.

[14] A. J. Montaño-Loza, J. C. Crispín-Acuña, J. M. Remes-Troche, and M. Uribe, "Abnormal hepatic biochemistries and clinical liver disease in patients with primary Sjögren's syndrome," Annals of Hepatology, vol. 6, no. 3, pp. 150-155, 2007.

[15] P. Invernizzi, "Liver auto-immunology: the paradox of autoimmunity in a tolerogenic organ," Journal of Autoimmunity, vol. 46, pp. 1-6, 2013.

[16] M.-R. Lee, H. Park, S. Bae et al., "Urinary Bisphenol A concentrations are associated with abnormal liver function in the elderly: a repeated panel study," Journal of Epidemiology \& Community Health, 2013.

[17] Z. K. Hassan, M. A. Elobeid, P. Virk et al., "Bisphenol A induces hepatotoxicity through oxidative stress in rat model," Oxidative Medicine and Cellular Longevity, vol. 2012, Article ID 194829, 6 pages, 2012.

[18] J. Wang, X. Shi, Y. Du, and B. Zhou, "Effects of xenoestrogens on the expression of vitellogenin $(v t g)$ and cytochrome P450 aromatase (cyp19a and $b$ ) genes in zebrafish (Danio rerio) larvae," Journal of Environmental Science and Health A: Toxic/Hazardous Substances and Environmental Engineering, vol. 46, no. 9, pp. 960-967, 2011.

[19] M. R. Namazi, "Cytochrome-P450 enzymes and autoimmunity: expansion of the relationship and introduction of free radicals as the link," Journal of Autoimmune Diseases, vol. 6, article 4, 2009.

[20] L. E. Padgett, K. A. Broniowska, P. A. Hansen, J. A. Corbett, and $\mathrm{H}$. M. Tse, "The role of reactive oxygen species and proinflammatory cytokines in type 1 diabetes pathogenesis," Annals of the New York Academy of Sciences, vol. 1281, pp. 16-35, 2013.

[21] H. S. Lee, M. Y. Pyo, and M. Yang, "Set, a putative oncogene, as a biomarker for prenatal exposure to Bisphenol A," Asian Pacific Journal of Cancer Prevention, vol. 13, no. 6, pp. 2711-2715, 2012.

[22] L. E. Padgett, K. A. Broniowska, P. A. Hansen, J. A. Corbett, and H. M. Tse, "The role of reactive oxygen species and proinflammatory cytokines in type 1 diabetes pathogenesis," Annals of the New York Academy of Sciences, vol. 1281, pp. 16-35, 2013.

[23] L.-Y. Yu-Lee, "Prolactin modulation of immune and inflammatory responses," Recent Progress in Hormone Research, vol. 57, pp. 435-455, 2002.

[24] L. Matera, M. Mori, and A. Galetto, "Effect of prolactin on the antigen presenting function of monocyte-derived dendritic cells," Lupus, vol. 10, no. 10, pp. 728-734, 2001.

[25] A. de Bellis, A. Bizzarro, R. Pivonello, G. Lombardi, and A. Bellastella, "Prolactin and autoimmunity," Pituitary, vol. 8, no. 1, pp. 25-30, 2005.

[26] S. Shelly, M. Boaz, and H. Orbach, "Prolactin and autoimmunity," Autoimmunity Reviews, vol. 11, no. 6-7, pp. A465-A470, 2012.

[27] R. Steinmetz, N. G. Brown, D. L. Allen, R. M. Bigsby, and N. Ben-Jonathan, "The environmental estrogen Bisphenol A stimulates prolactin release in vitro and in vivo," Endocrinology, vol. 138, no. 5, pp. 1780-1786, 1997.

[28] J. Hao, J. Wang, W. Zhao, L. Ding, E. Gao, and W. Yuan, "Effect of Bisphenol A exposure on sex hormone level in occupational women," Wei Sheng Yan Jiu, vol. 40, no. 3, pp. 312-314, 2011.
[29] S. Shelly, M. Boaz, and H. Orbach, "Prolactin and autoimmunity," Autoimmunity Reviews, vol. 11, no. 6-7, pp. A465-A470, 2012.

[30] M. Alizadeh, F. Ota, K. Hosoi, M. Kato, T. Sakai, and M. A. Satter, "Altered allergic cytokine and antibody response in mice treated with Bisphenol A," The Journal of Medical Investigation, vol. 53, no. 1-2, pp. 70-80, 2006.

[31] A. Elango, B. Shepherd, and T. T. Chen, "Effects of endocrine disrupters on the expression of growth hormone and prolactin mRNA in the rainbow trout pituitary," General and Comparative Endocrinology, vol. 145, no. 2, pp. 116-127, 2006.

[32] L. O. Chailurkit, W. Aekplakorn, and B. Ongphiphadhanakul, "The relationship between circulating estradiol and thyroid autoimmunity in males," European Journal of Endocrinology, vol. 170, no. 1, pp. 63-67, 2013.

[33] C. Chighizola and P. L. Meroni, "The role of environmental estrogens and autoimmunity," Autoimmunity Reviews, vol. 11, no. 6-7, pp. A493-A501, 2012.

[34] R. Panchanathan, H. Liu, and D. Choubey, "Expression of murine Unc93b1 is up-regulated by interferon and estrogen signaling: implications for sex bias in the development of autoimmunity," International Immunology, vol. 25, no. 9, pp. 521-529, 2013.

[35] E. Incorvaia, L. Sicouri, S. K. Petersen-Mahrt, and K. M. Schmitz, "Hormones and AID: balancing immunity and autoimmunity," Autoimmunity, vol. 46, no. 2, pp. 128-137, 2013.

[36] M. Cunningham and G. Gilkeson, "Estrogen receptors in immunity and autoimmunity," Clinical Reviews in Allergy and Immunology, vol. 40, no. 1, pp. 66-73, 2011.

[37] T.-C. Chao, P. J. van Alten, J. A. Greager, and R. J. Walter, "Steroid sex hormones regulate the release of tumor necrosis factor by macrophages," Cellular Immunology, vol. 160, no. 1, pp. 4349, 1995.

[38] R. Panchanathan and D. Choubey, "Murine BAFF expression is up-regulated by estrogen and interferons: implications for sex bias in the development of autoimmunity," Molecular Immunology, vol. 53, no. 1-2, pp. 15-23, 2013.

[39] M. C. Siracusa, M. G. Overstreet, F. Housseau, A. L. Scott, and S. L. Klein, " $17 \beta$-estradiol alters the activity of conventional and IFN-producing killer dendritic cells," The Journal of Immunology, vol. 180, no. 3, pp. 1423-1431, 2008.

[40] R. S. Bonds and T. Midoro-Horiuti, "Estrogen effects in allergy and asthma," Current Opinion in Allergy \& Clinical Immunology, vol. 13, no. 1, pp. 92-99, 2013.

[41] J. A. Rogers, L. Metz, and V. W. Yong, "Review: endocrine disrupting chemicals and immune responses: a focus on Bisphenol-A and its potential mechanisms," Molecular Immunology, vol. 53, no. 4, pp. 421-430, 2013.

[42] N. Ben-Jonathan and R. Steinmetz, "Xenoestrogens: the emerging story of Bisphenol A," Trends in Endocrinology and Metabolism, vol. 9, no. 3, pp. 124-128, 1998.

[43] J.-Y. Youn, H.-Y. Park, J.-W. Lee et al., "Evaluation of the immune response following exposure of mice to Bisphenol A: induction of Th1 cytokine and prolactin by BPA exposure in the mouse spleen cells," Archives of Pharmacal Research, vol. 25, no. 6, pp. 946-953, 2002.

[44] J. A. Rogers, L. Metz, and V. W. Yong, "Review: endocrine disrupting chemicals and immune responses: a focus on Bisphenol-A and its potential mechanisms," Molecular Immunology, vol. 53, no. 4, pp. 421-430, 2013. 
[45] L. Canesi, M. Betti, L. C. Lorusso, C. Ciacci, and G. Gallo, “In vivo' effects of Bisphenol A in Mytilus hemocytes: modulation of kinase-mediated signalling pathways," Aquatic Toxicology, vol. 71, no. 1, pp. 73-84, 2005.

[46] G. Wildner and U. Kaufmann, "What causes relapses of autoimmune diseases? The etiological role of autoreactive T cells," Autoimmunity Reviews, vol. 12, no. 11, pp. 1070-1075, 2013.

[47] S. André, D. F. Tough, S. Lacroix-Desmazes, S. V. Kaveri, and J. Bayry, "Surveillance of antigen-presenting cells by $\mathrm{CD} 4{ }^{+} \mathrm{CD} 25^{+}$ regulatory $\mathrm{T}$ cells in autoimmunity: immunopathogenesis and therapeutic implications," The American Journal of Pathology, vol. 174, no. 5, pp. 1575-1587, 2009.

[48] T. Wu and C. Mohan, "The AKT axis as a therapeutic target in autoimmune diseases," Endocrine, Metabolic \& Immune Disorders-Drug Targets, vol. 9, no. 2, pp. 145-150, 2009.

[49] K. D. Moudgil and D. Choubey, "Cytokines in autoimmunity: role in induction, regulation, and treatment," Journal of Interferon \& Cytokine Research, vol. 31, no. 10, pp. 695-703, 2011.

[50] L. Pisapia, G. del Pozzo, P. Barba et al., "Effects of some endocrine disruptors on cell cycle progression and murine dendritic cell differentiation," General and Comparative Endocrinology, vol. 178, no. 1, pp. 54-63, 2012.

[51] S. Yoshino, K. Yamaki, X. Li et al., "Prenatal exposure to Bisphenol A up-regulates immune responses, including T helper 1 and T helper 2 responses, in mice," Immunology, vol. 112, no. 3, pp. 489-495, 2004.

[52] M. Goto, Y. Takano-Ishikawa, H. Ono, M. Yoshida, K. Yamaki, and H. Shinmoto, "Orally administered Bisphenol A disturbed antigen specific immunoresponses in the naïve condition," Bioscience, Biotechnology and Biochemistry, vol. 71, no. 9, pp. 21362143, 2007.

[53] K. M. Pollard, D. M. Cauvi, C. B. Toomey, K. V. Morris, and D. H. Kono, "Interferon- $\gamma$ and systemic autoimmunity," Discovery Medicine, vol. 16, no. 87, pp. 123-131, 2013.

[54] J.-Y. Youn, H.-Y. Park, J.-W. Lee et al., "Evaluation of the immune response following exposure of mice to Bisphenol A: induction of Th1 cytokine and prolactin by BPA exposure in the mouse spleen cells," Archives of Pharmacal Research, vol. 25, no. 6, pp. 946-953, 2002.

[55] A. Weaver, A. Goncalves da Silva, R. K. Nuttall et al., "An elevated matrix metalloproteinase (MMP) in an animal model of multiple sclerosis is protective by affecting Th1/Th2 polarization,” The FASEB Journal, vol. 19, no. 12, pp. 1668-1670, 2005.

[56] H. Yan, M. Takamoto, and K. Sugane, "Exposure to Bisphenol A prenatally or in adulthood promotes TH2 cytokine production associated with reduction of $\mathrm{CD} 4{ }^{+} \mathrm{CD} 25^{+}$regulatory $\mathrm{T}$ cells," Environmental Health Perspectives, vol. 116, no. 4, pp. 514-519, 2008.

[57] J. S. Ellis, S. H. Hong, H. Zaghouani, and H. Braley-Mullen, "Reduced effectiveness of $\mathrm{CD} 4^{+} \mathrm{Foxp} 3^{+}$regulatory $\mathrm{T}$ cells in CD28-deficient NOD.H-2h4 mice leads to increased severity of spontaneous autoimmune thyroiditis," The Journal of Immunology, vol. 191, no. 10, pp. 4940-4949, 2013.

[58] M. Maes, M. Kubera, J. C. Leunis, M. Berk, M. Geffard, and E. Bosmans, "In depression, bacterial translocation may drive inflammatory responses, oxidative and nitrosative stress (O\&NS), and autoimmune responses directed against O\&NSdamaged neoepitopes," Acta Psychiatrica Scandinavica, vol. 127, no. 5, pp. 344-354, 2013.

[59] A. Igarashi, S. Ohtsu, M. Muroi, and K.-I. Tanamoto, "Effects of possible endocrine disrupting chemicals on bacterial component-induced activation of NF- $\kappa$ B," Biological and Pharmaceutical Bulletin, vol. 29, no. 10, pp. 2120-2122, 2006.

[60] K. Stechova, R. Pomahacova, J. Hrabak et al., "Reactivity to helicobacter pylori antigens in patients suffering from thyroid gland autoimmunity," Experimental and Clinical Endocrinology and Diabetes, vol. 117, no. 8, pp. 423-431, 2009.

[61] J. Banchereau and R. M. Steinman, "Dendritic cells and the control of immunity," Nature, vol. 392, no. 6673, pp. 245-252, 1998.

[62] P. Kaliński, C. M. U. Hilkens, E. A. Wierenga, and M. L. Kapsenberg, "T-cell priming by type- 1 and type- 2 polarized dendritic cells: the concept of a third signal," Immunology Today, vol. 20, no. 12, pp. 561-567, 1999.

[63] H. Guo, T. Liu, Y. Uemura et al., "Bisphenol A in combination with TNF- $\alpha$ selectively induces Th2 cell-promoting dendritic cells in vitro with an estrogen-like activity," Cellular and Molecular Immunology, vol. 7, no. 3, pp. 227-234, 2010.

[64] H. Kolb and V. Kolb-Bachofen, "Nitric oxide in autoimmune disease: cytotoxic or regulatory mediator?" Immunology Today, vol. 19, no. 12, pp. 556-561, 1998.

[65] J.-A. Byun, Y. Heo, Y.-O. Kim, and M.-Y. Pyo, "Bisphenol Ainduced downregulation of murine macrophage activities in vitro and ex vivo," Environmental Toxicology and Pharmacology, vol. 19, no. 1, pp. 19-24, 2005.

[66] H. H. Smits, "B cells in allergic diseases: bad or better?" Autoimmunity, vol. 45, no. 5, pp. 415-426, 2012.

[67] M. H. Lee, S. W. Chung, B. Y. Kang et al., "Enhanced interleukin4 production in $\mathrm{CD}^{+} \mathrm{T}$ cells and elevated immunoglobulin $\mathrm{E}$ levels in antigen-primed mice by Bisphenol A and nonylphenol, endocrine disruptors: involvement of nuclear factor-AT and $\mathrm{CA}^{2+,}$, Immunology, vol. 109, no. 1, pp. 76-86, 2003.

[68] S. Altrichter, H.-J. Peter, D. Pisarevskaja, M. Metz, P. Martus, and M. Maurer, "Ige mediated autoallergy against thyroid peroxidase-a novel pathomechanism of chronic spontaneous urticaria?" PLoS ONE, vol. 6, no. 4, Article ID e14794, 2011.

[69] H. Yurino, S. Ishikawa, T. Sato et al., "Endocrine disruptors (environmental estrogens) enhance autoantibody production by B1 cells," Toxicological Sciences, vol. 81, no. 1, pp. 139-147, 2004.

[70] T. Hiroi, K. Okada, S. Imaoka, M. Osada, and Y. Funae, "Bisphenol A binds to protein disulfide isomerase and inhibits its enzymatic and hormone-binding activities," Endocrinology, vol. 147, no. 6, pp. 2773-2780, 2006.

[71] K. Okada, S. Imaoka, S. Hashimoto, T. Hiroi, and Y. Funae, "Over-expression of protein disulfide isomerase reduces the release of growth hormone induced by Bisphenol A and/or T3," Molecular and Cellular Endocrinology, vol. 278, no. 1-2, pp. 4451, 2007.

[72] S. Tapryal, V. Gaur, K. J. Kaur, and D. M. Salunke, "Structural evaluation of a mimicry-recognizing paratope: plasticity in antigen-antibody interactions manifests in molecular mimicry," The Journal of Immunology, vol. 191, no. 1, pp. 456-463, 2013.

[73] K. Moriyama, T. Tagami, T. Akamizu et al., "Thyroid hormone action is disrupted by Bisphenol A as an antagonist," Journal of Clinical Endocrinology and Metabolism, vol. 87, no. 11, pp. 51855190, 2002.

[74] J. M. Davies, "Molecular mimicry: can epitope mimicry induce autoimmune disease?" Immunology and Cell Biology, vol. 75, no. 2, pp. 113-126, 1997. 
[75] J. D. McKinney and C. L. Waller, "Molecular determinants of hormone mimicry: halogenated aromatic hydrocarbon environmental agents," Journal of Toxicology and Environmental Health B: Critical Reviews, vol. 1, no. 1, pp. 27-58, 1998.

[76] N. T. Nguyen, T. Nakahama, and T. Kishimoto, "Aryl hydrocarbon receptor and experimental autoimmune arthritis," Seminars in Immunopathology, vol. 35, no. 6, pp. 637-644, 2013.

[77] K. Takahashi, "Chemical contamination of the environment and development of allergic and autoimmune diseases," Nippon Rinsho, vol. 68, no. 3, pp. 551-562, 2010. 


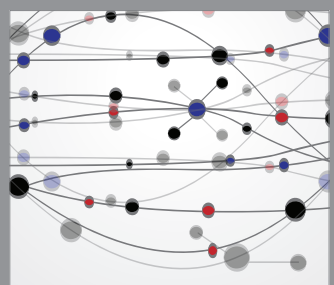

The Scientific World Journal
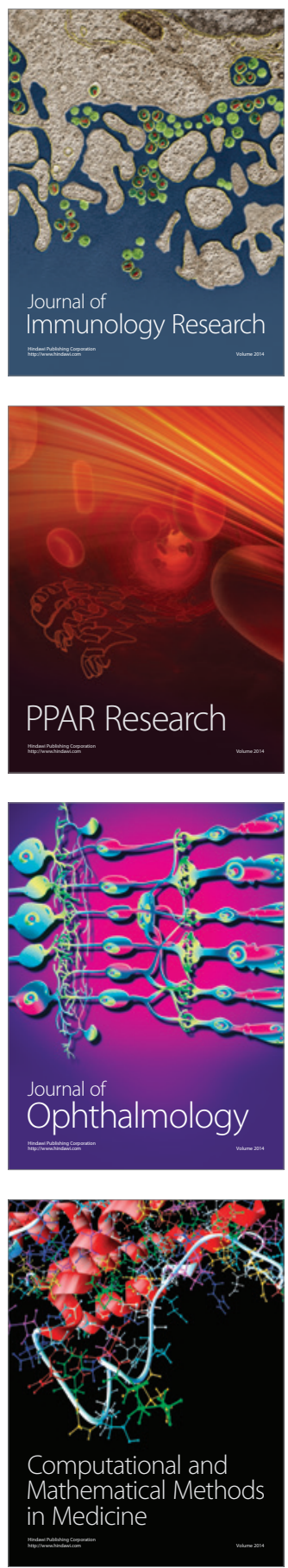

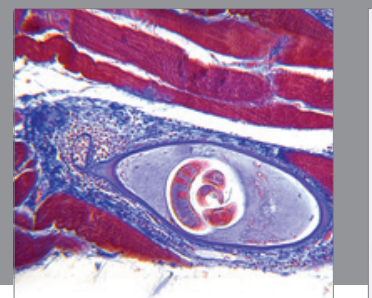

Gastroenterology

Research and Practice
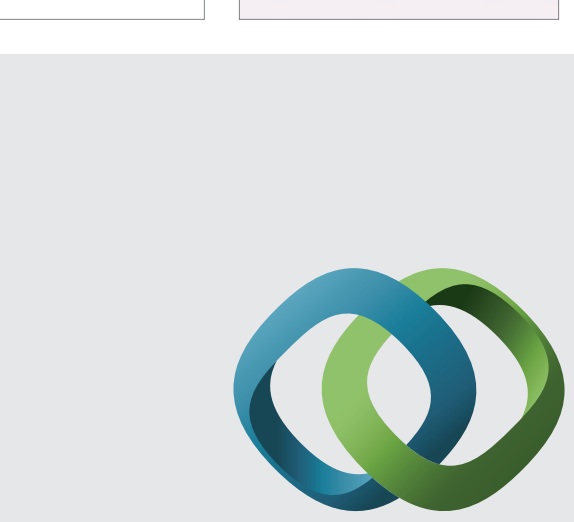

\section{Hindawi}

Submit your manuscripts at

http://www.hindawi.com
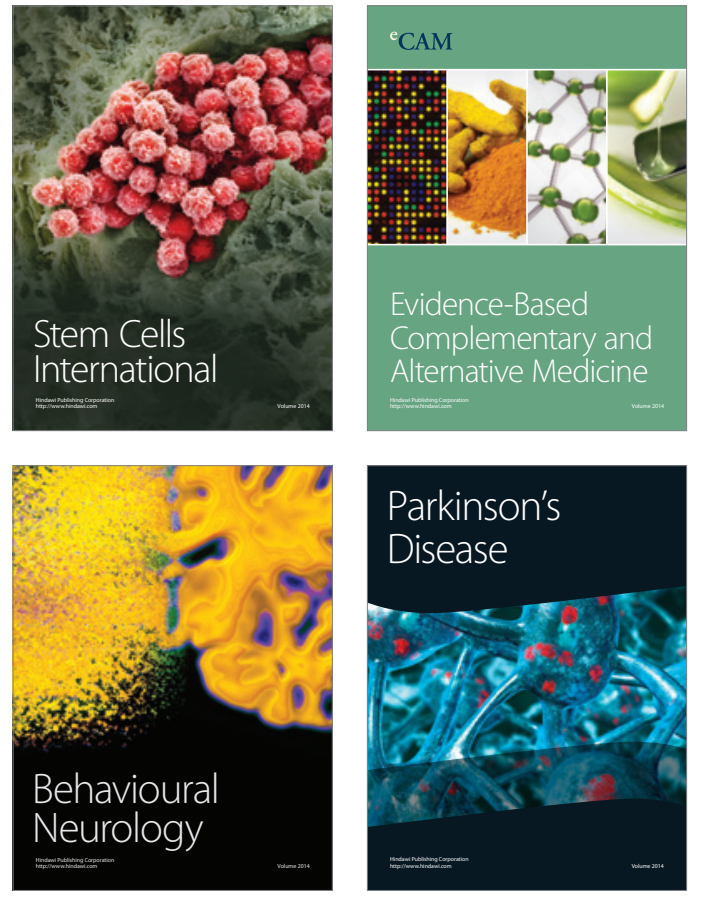
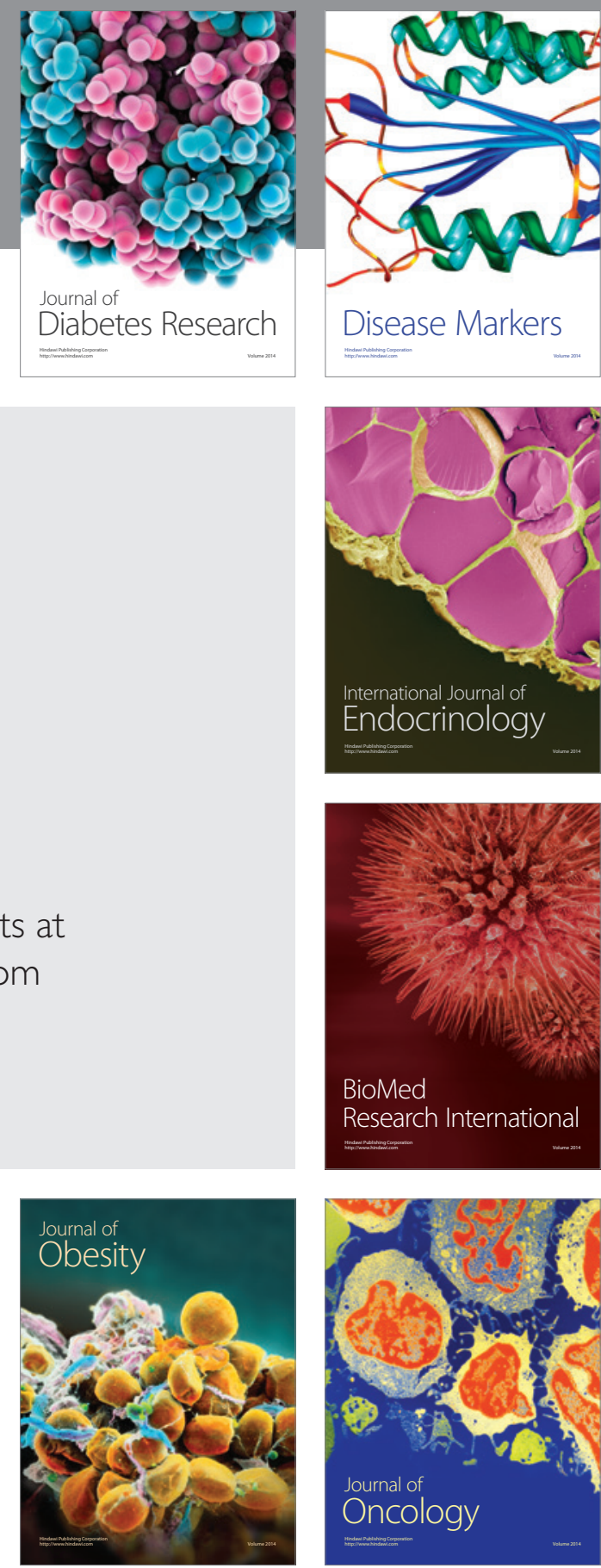

Disease Markers
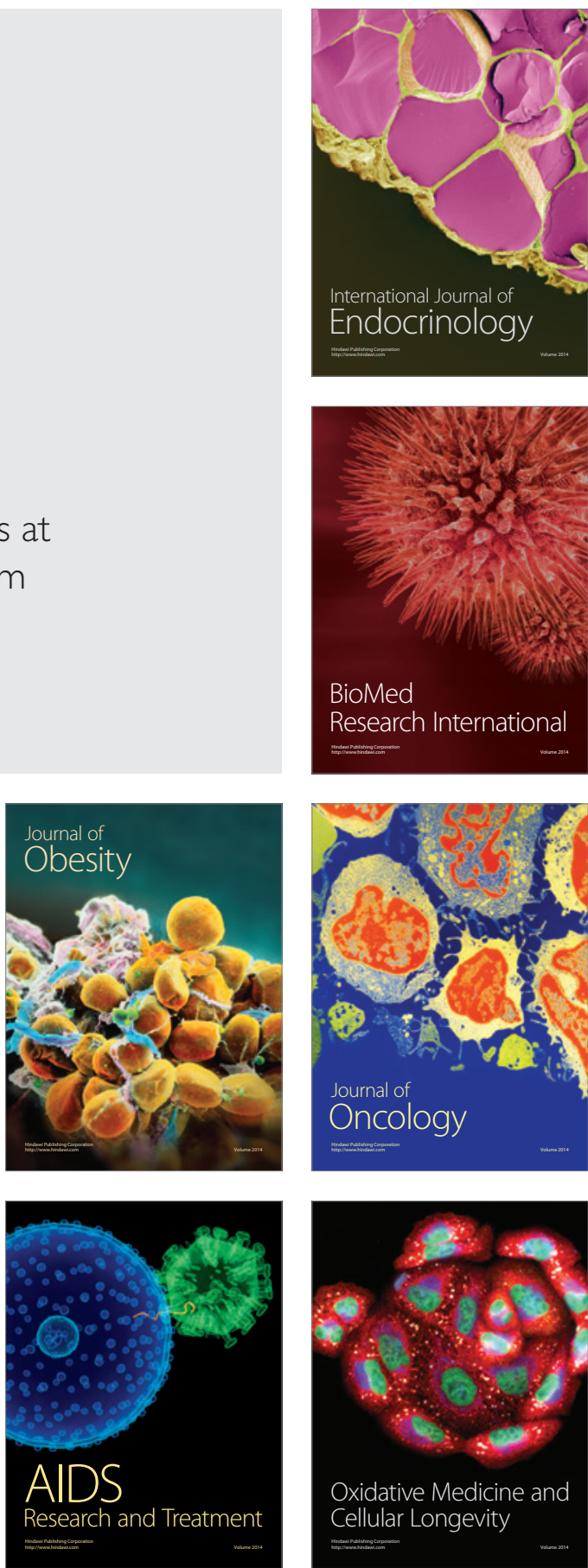